\title{
Research Article \\ Bulk Heterojunction Organic Solar Cell Area-Dependent Parameter Fluctuation
}

\author{
A. J. Trindade and L. Pereira \\ Department of Physics and i3N, Institute for Nanostructures, Nanomodelling and Nanofabrication, University of Aveiro, Santiago \\ Campus, 3810-193 Aveiro, Portugal \\ Correspondence should be addressed to L. Pereira; luiz@ua.pt
}

Received 30 April 2017; Accepted 28 August 2017; Published 25 October 2017

Academic Editor: Mark van Der Auweraer

Copyright ( 2017 A. J. Trindade and L. Pereira. This is an open access article distributed under the Creative Commons Attribution License, which permits unrestricted use, distribution, and reproduction in any medium, provided the original work is properly cited.

\begin{abstract}
Organic solar cell efficiency is known to be active area dependent and is usually a problem in the upscale factor for market applications. In this work, a detailed study of organic photovoltaic devices with active layer based on poly(3-hexylthiophene) (P3HT) and 1-(3-methoxycarbonyl)-propyl-1-phenyl- $(6,6) \mathrm{C}_{61}(\mathrm{PCBM})$ is made, evaluating the effect of the change on the active area from $10^{-2}$ to $4 \mathrm{~cm}^{4}$. The device structure was kept simple in order to allow the understanding of the physical effects involved. Device figures of merit were extracted from the equivalent circuit using a genetic-based algorithm, and their relationship with the active area was compared. It is observed that the efficiency drops significantly with the active area increase (as the fill factor) while the parallel and series resistance, adjusted to the active area, seems to be relatively constant and increases linearly, respectively. The short circuit current and the generated photocurrent also drop significantly with the active area increase. The open circuit voltage does not show major changes. These results are discussed considering the main influences for the observed efficiency data. Particularly, as the basic circuit model seems to fail to explain the macroscopic results, the behavior can be related with the enlargement of defect interaction.
\end{abstract}

\section{Introduction}

As organic solar cells are achieving efficiencies and lifetimes closer to the minimum required for commercialization, there is the need to study different modulus disposition, size, electrical connections, and individual cell behavior [1-17]. While high efficiency modules have been reported, these (as a rule of thumb) only seem to occur on small-scale laboratory devices. While such areas are not practical for mass production and reveal a highly complex and costly manufacturing process, there is the need to optimize and model the cells' behavior on a real-world real-size scale. While other architectures can lead to efficiency increase and better charge collection at the electrodes, the methods and materials used are expensive and highly reactive, degrade quickly, and add a higher level of complexity to the final device [18-20]. All of which comes at a price for the consumer and to the manufacturing yield. Different architectures emerged on the last years trying to bring a new answer to the limitations of charge transport of the organic materials. Even with its own limitations, the most promising is still the bulk heterojunction type, where some experimental results point to a maximum efficiency of about 13\% [21] although in a very complex structure and in a small size active area.

Bulk heterojunction (BHJ) solar cells have been extensively studied considering applications in the market [22-25]. However, there is still extensive work to be done regarding the study of their electrical behavior. While efficiency records (in more realistic structures) near $10 \%$ have been reported [26-28], these seem to occur on very small laboratory-scale devices. At this moment, the major studies with organic solar cells need to be focused in general device structure and/or composition of the active layers [29-33] as well some novel materials with improved performance [34-37]. As this is not compatible with industrial scales and mass production, there is the need to study the effects of the upscale of such devices and address the loss of performance, efficiency $(\eta)$, fill factor (FF), and fluctuations 
on the parallel $\left(R_{\mathrm{P}}\right)$ and serial $\left(R_{\mathrm{S}}\right)$ resistances. Also, the diode ideality $(n)$, the generated photocurrent $\left(J_{\mathrm{PH}}\right)$, and the typical open circuit voltage $\left(V_{\mathrm{OC}}\right)$ and short circuit current $\left(J_{\mathrm{SC}}\right)$ must be addressed.

Several studies have been done to understand the influence of the BHJ active area on the device properties. Such studies involve in particular the relationship between the serial resistance and the $\mathrm{BHJ}$ performance $[38,39]$. Recent analytical and experimental work shows that the degradation of the solar cell performance can be attributed to the higher series resistance associated with the active area increase [40-43]. Some physical studies were also made showing that other factors besides the series resistance must be also responsible for the changes in the $\mathrm{BHJ}$ device with the increase of the active area [44].

In the present work, the simplest $\mathrm{BHJ}$ device architecture was made on a substrate with an indium tin oxide (ITO) anode/hole-injection layer (PEDOT:PSS)/bulk heterojunction layer (P3HT:PCBM)/the cathode of aluminum. The analysis of the solar cell parameter fluctuation towards the increase of active illuminated areas is performed and related to the increasing bulk recombination which occurred in the process. The solar cell equation parameters regarding the device characteristics $\left(\eta, R_{\mathrm{S}}, R_{\mathrm{P}}, n, \mathrm{FF}, J_{\mathrm{PH}}, V_{\mathrm{OC}}\right.$, and $\left.J_{\mathrm{SC}}\right)$ were adjusted and proven to be area dependent. The data shows a slight dependence of the open-circuit voltage $\left(V_{\mathrm{OC}}\right)$ value that can be correlated with some light intensity as the area increases. The fill factor of the solar cell decreases significantly with the area increase mostly due to both drastic drops in the produced photocurrent contrasting with the inferior $V_{\mathrm{OC}}$ increase. The electric power produced increases accordingly with the $V_{\mathrm{OC}}$ increase as the latest is area and light intensity dependent. The diode ideality factor $(n)$ also grows as the active area increases, representing the increase of intrinsic defects that behave as existing recombination centers. The parallel resistance $\left(R_{\mathrm{P}}\right)$ plummets on this situation. This shows the ever growing leakage currents within the device that drives the excitons to a recombination state where the photo-generated holes and electrons no longer exist as separate entities to be collected throughout the material. Finally, we can verify that the typical equivalent electrical circuit partially fails to represent all these parameters fluctuations.

All these fluctuations between real device and physical parameters need to be accounted when considering the active area increase for a real-life product application to the end consumer.

\section{Experimental}

The bulk heterojunction solar cells were fabricated using indium thin oxide- (ITO-) coated glass (Delta Technologies) having a $12-14 \Omega / \mathrm{cm}^{2}$ sheet resistance and a maximum active area of $2 \times 2 \mathrm{~cm}^{2}$. Substrates were first cleaned through an ultrasonic bath using detergent $(10 \mathrm{~min})$, acetone (20 $\mathrm{min})$, isopropanol (20 min), and distilled water $(20 \mathrm{~min})$. The different layers composing the device were deposited sequentially. A hole-injection layer (HTL) of PEDOT:PSS (Agfa, high conductivity) was spin coated at $3.000 \mathrm{rpm}$ during 30 seconds followed by thermal annealing at $120^{\circ} \mathrm{C}$ for 15 minutes in the oven $(\sim 50 \mathrm{~nm}$ by perfilometry measurements). The active layer is composed of P3HT and PCMB (Sigma-Aldrich, sublimated) on a ratio $1: 1$ in chloroform $(20 \mathrm{mg} / \mathrm{ml})$, spin-coated at $2000 \mathrm{rpm}$ for 30 seconds. The thermal annealing conditions were performed in order to minimize surface roughness and allow for the best conformation possible for the polymer chains. The used solvent was therefore evaporated at $50^{\circ} \mathrm{C}$ during 1 hour $(\sim 250 \mathrm{~nm}$ by perfilometry measurements). The aluminum cathode was thermally evaporated on the active layer through a shadow mask at $<10^{-6}$ Torr, and the devices were not encapsulated. Figure 1 shows a schematic diagram of the layer deposition sequence and final device architecture.

Current-voltage data was acquired using a Keithley K2410 Voltage Source Meter at room temperature using an AM1.5 Global Oriel NRC-96000 Solar Simulator, and the active area increase was performed using black cardboard masks avoiding the well-known edge effects [45] as only the "nominal" active area is illuminated and tested. In this case, the electrical current is lower than the obtained when the whole region is illuminated (including the edges) but represents a more "real" situation. In Figure 1(c), the performed increase of the measured active area can be seen superimposed on the final device active area.

\section{Results and Discussion}

In order to extract the figures of merit of the device, we can use the one-diode "real" solar cell model (shown in Figure 2), typically given by the general equation [46, 47]:

$$
J(V)=J_{0}\left(\exp \frac{q\left(V-J R_{\mathrm{S}} A\right)}{n k_{\mathrm{B}} T}-1\right)+\frac{V-J R_{\mathrm{S}} A}{R_{\mathrm{P}}}-J_{\mathrm{PH}},
$$

where $J_{0}$ is the diode saturation current density, $q$ the electronic charge, $n$ the diode ideality factor, $k_{\mathrm{B}}$ the Boltzmann constant, $T$ the temperature, $A$ the cell active area, and $V$ the device voltage. In this case, we consider $J_{\mathrm{PH}}$ voltage independent. A discussion about such question will be done later.

The resistances included in the equation considerably alter the shape of the curve since the voltage $V\left(R_{\mathrm{S}}\right)=J \times R_{\mathrm{S}}$ decreases along the series resistance, while in parallel adds the current $J_{\mathrm{P}}=V-J \times R_{\mathrm{S}} / R_{\mathrm{P}}$ to the current produced. The $R_{\mathrm{P}}$ value can be estimated by determining the slope of the $J-V$ curve in the region of voltage values lower than zero voltage, because in the reverse voltage region the diode does not conduct substantially and therefore the current is determined only by resistors $R_{\mathrm{S}}$ and $R_{\mathrm{P}}$. The $R_{\mathrm{S}}$ can be estimated by the slope of the $J-V$ curve when the applied voltage is higher than the $V_{\mathrm{OC}}$ because the current flowing through the diode is higher than the current that flows through $R_{\mathrm{P}}$, whereby the dominant resistance is $R_{\mathrm{S}}$. So, in a first approximation, we can write $R_{\mathrm{P}} \approx(V / J A)_{V<0}$ and $R_{\mathrm{S}} \approx(V / J A)_{V>V_{\mathrm{OC}}}$ and we use such information for starting points in the genetic algorithm. Series and parallel resistances have been both associated to losses of charge generation (recombination), layer defects from the deposition method, material impurities, 


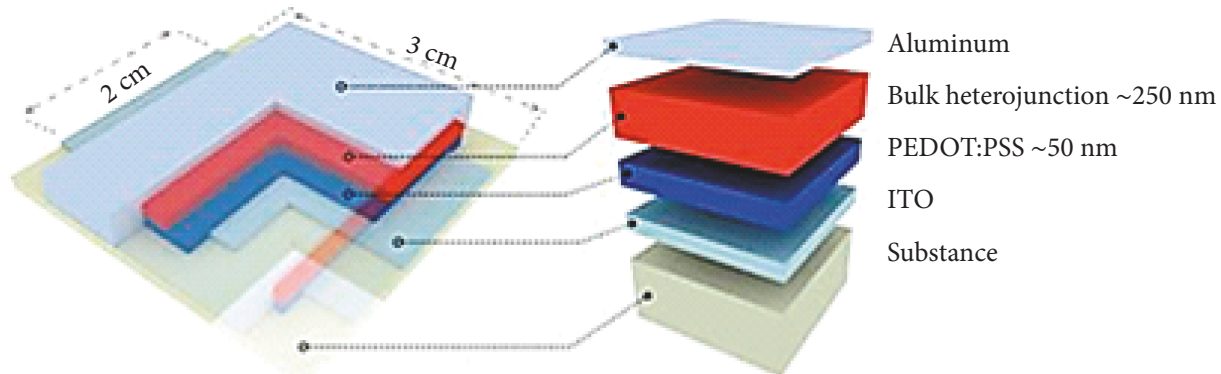

(a)

(b)

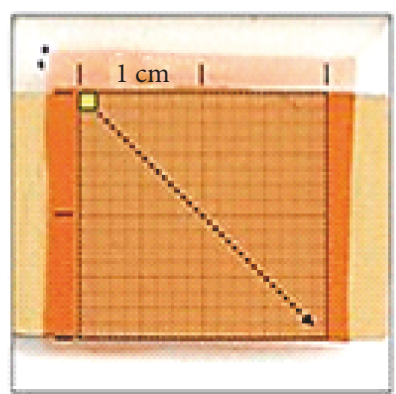

(c)

Figure 1: (a) Device layout overview and dimensions. (b) Sequentially deposited layers. (c) Example of the final device and active area mapping increase from the initial dimension $\left(0.1 \times 0.1 \mathrm{~cm}^{2}\right)$ to the maximum available active area $\left(2 \times 2 \mathrm{~cm}^{2}\right)$.

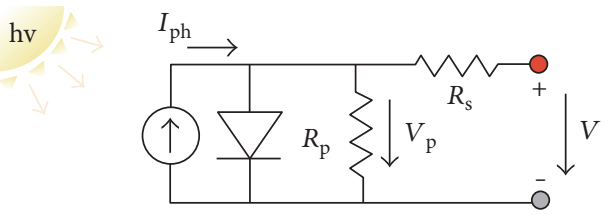

(a)

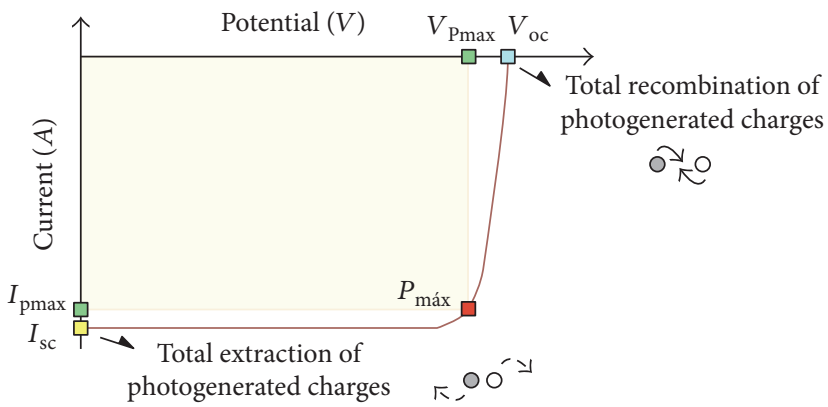

(b)

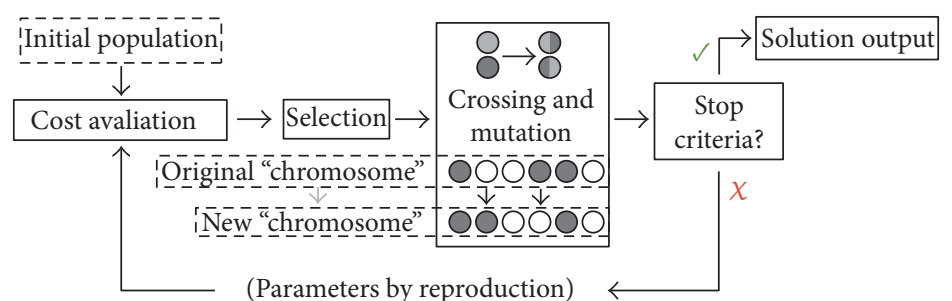

(c)

Figure 2: (a) Equivalent circuit used to modulate the organic solar cell parameters. (b) Typical current-voltage behavior of a solar cell and the relevant points to be considered in order to calculate all figures of merit and the efficiency. The rectangle inside the $I$ - $V$ curve gives the fill factor as well as the maximum generated power. (c) Simple scheme of the genetic algorithm flow used for the simulations.

interface materials, and energy level misalignment, among other effects reducing charge transport before it can be successfully collected by the electrodes.

In order to model the device performance and characteristics, a theoretical simulation based on the acquired $J-V$ curves was scripted in Matlab $^{\circledR}$. The extraction of some parameters is performed initially through adjustments to specific regions of interest in the graphs obtained $\left(I_{\mathrm{SC}}, V_{\mathrm{OC}}\right.$, maximum power $\left(P_{\max }\right)$, and FF). These values are then compared to those obtained from the simulation carried out. The fit to the experimental data was performed using the equations of the real equivalent circuit. The parameters to be obtained from the device allow characterization and quantification of the operating values for the components 


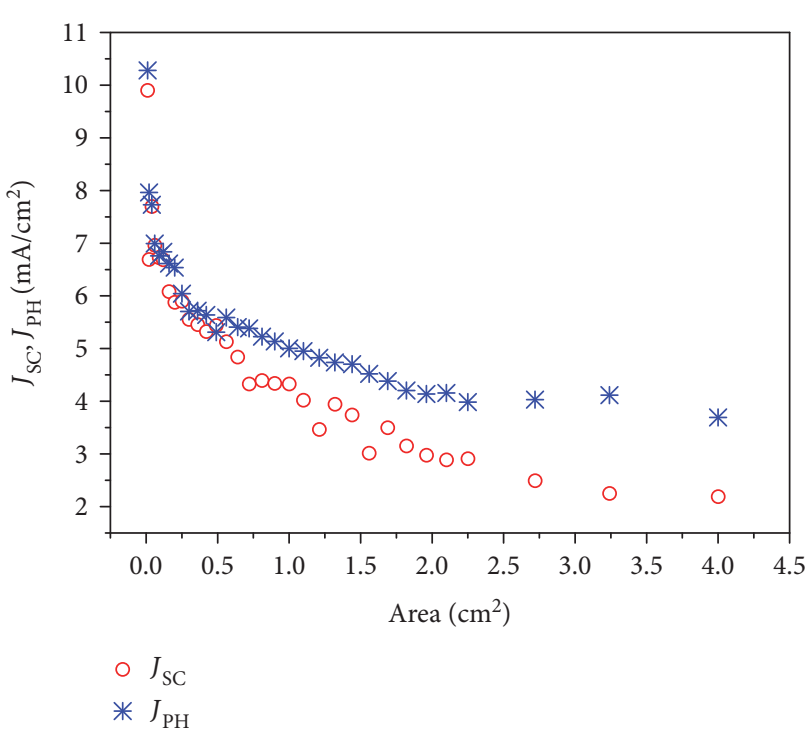

(a)

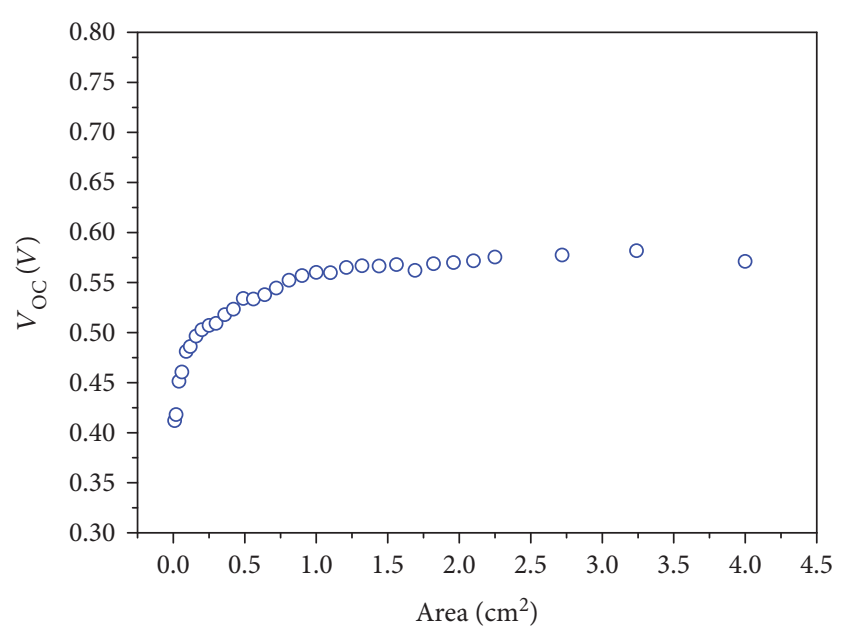

(b)

Figure 3: (a) Extrapolated short-circuit current and simulated photocurrent from the device. (b) Open-circuit voltage of the device regarding the measured active area.

that comprise the equivalent circuit, these being (scheme indicated in Figure 2(c))

$$
\text { Parameters }=\left(n, J_{\mathrm{PH}}, J_{0}, R_{\mathrm{S}}, R_{\mathrm{P}}\right) \text { (“real circuit"). }
$$

The algorithm was implemented to fit an evolutionary algorithm (genetic algorithm) in order to seek the best fit to the experimental points using the equations used to model inorganic devices. The genetic algorithm method is an optimization and search numerical analysis based on the concept of natural evolution (genetic inheritance and Darwinian strife to survival [48]). Besides such natural approach, the genetic algorithm does not include (contrarily from almost other methods) the calculation of derivatives (that sometimes makes the convergence more problematic) and becomes to be successfully applied in several fields of scientific research and technology, including solid-state devices [49]. Our real problem is to extract the correct information of all device parameters. Using a simplex optimization method, operating limits are established for parameters (Lower and Upper Bounds) restricting the adjustment "evolution." The population of solutions is randomly generated, and the algorithm searches in the defined domain, a near point for the best solution that take into account a minimization problem of the cost function (error). The simulation performed allowed to inquire about the parameter fluctuation as the active area increases, giving valuable insight regarding final device dimensions for manufacturing and real-module test purposes [50, 51].

In the study of the parameter fluctuation, the active area increases from $10^{-2} \mathrm{~cm}^{2}$ to $4 \mathrm{~cm}^{2}$ in squared shapes increasing millimeter by millimeter side until the maximum active area. As a first result, we can see a global drop in current production and a small gain in the open-circuit voltage. The $J-V$ shape changes indicate, in a first approximation, that the $R_{\mathrm{S}}$ increases as the active area increases. Naturally, this kind of behavior will change significantly the overall solar cell figures of merit. The simulated total photocurrent by the device is (as seen in Figure 3(a)) always paired with the short-circuit current. Increase in the measured shortcircuit causes the algorithm to recognize a higher produced photocurrent from the device, resulting in a better overlap of the experimental and simulated $J-V$ curves.

On an ideal device, these two parameters $\left(J_{\mathrm{PH}}\right.$ and $\left.J_{\mathrm{SC}}\right)$ would be completely matching one another. However, since $J_{\mathrm{PH}}$ comes from the numerical simulation, it must account for the losses occurring on the device performance (weighted within the device equation) and is usually higher than the measured short-current density. However, for the minimum area $\left(10^{-2} \mathrm{~cm}^{2}\right)$ - and for this type of architecture-the maximum current is achieved $\left(\sim 10 \mathrm{~mA} / \mathrm{cm}^{2}\right)$; once the area increases, a strong decay in the produced photocurrent is observed, going to values near half of the maximum initially achieved and even much less for higher active areas. The observed decay occurs as more material gets exposed to the incident radiation, demonstrating that an increase in the active area does not always translate on a higher current production but results in a higher number of recombination occurring in the material. With the active area increase, the extra produced photocurrent still surpasses the lost photocurrent due to recombination in the device and seems to slowly decay for areas superior to $1.82 \mathrm{~cm}^{2}$. The nonuniformity of the cells for the large area can contribute, in a first approximation, significantly to this result. The value of the $J_{0}$ exhibits a relatively large fluctuation, changing from 1 to near $100 \mu \mathrm{A} / \mathrm{cm}^{2}$ and cannot be correlated with any device area dependency. Such variations in that order of magnitude can be attributed in a first approximation to the algorithm minimization procedures, and due to its randomness with the device area, we expected no physical relationship. 


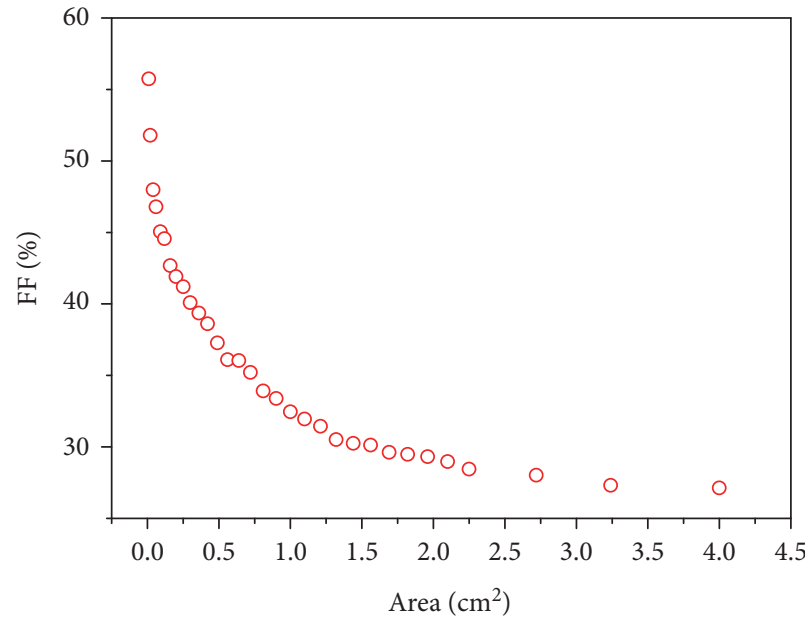

(a)

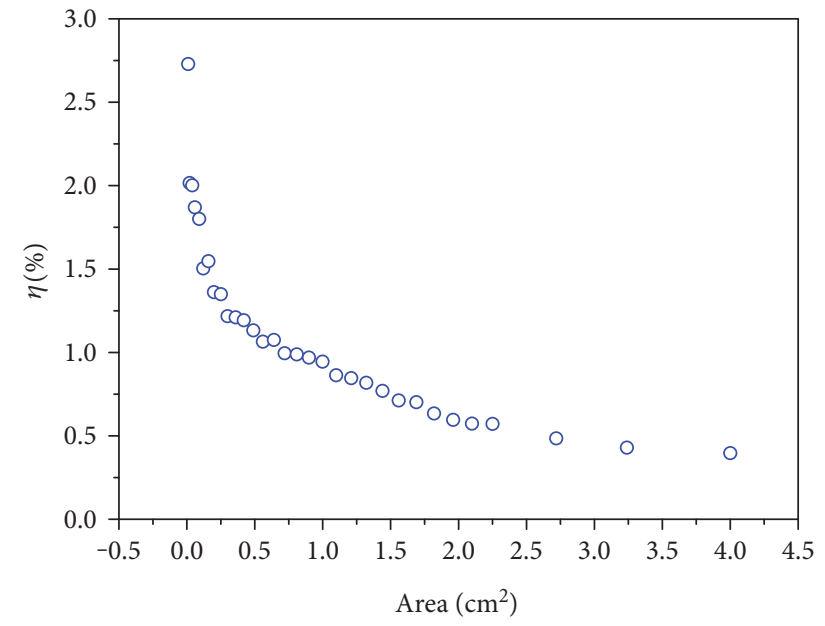

(b)

FIgURE 4: (a) Fill factor decay as active area increases. (b) Device efficiency decay towards a higher active area.

Regarding the open-circuit voltage $\left(V_{\mathrm{OC}}\right)$ - as it has been proven before by $[52,53]$-this parameter is incidentally radiation dependent but not necessarily dependent on the solar cell area [44]. As seen in Figure 3(b), gains in the open-source voltage from the initial area can add up to $+0.2 \mathrm{~V}$ on the final device behavior, providing a significant increase in the device power production. In the first approximation, we expect that the amount of radiation-exposed material that comprises the device is crucial for an efficient open-source voltage $\left(V_{\mathrm{OC}}\right)$ generation; but, as well known, the value of $V_{\mathrm{OC}}$ is much dependent on the junction properties of the donor and acceptor layers and on the difference of the work functions between the electrodes $[54,55]$. Therefore, it tends to be relatively constant (independent) with the active area. Although the changes are not much higher, such independence is not observed. The increase is not, however, linearly dependent, and in each initial dimension, increase from the original $10^{-2} \mathrm{~cm}^{2}$ results in a steady increase of $V_{\mathrm{OC}}$. The highest value measured occurred for the maximum area tested $\left(4 \mathrm{~cm}^{2}\right)$, where $0.6 \mathrm{~V}$ were achieved. This result can be simply explained, if we consider that some physical properties of the solar cells are not independent on the active area, confirmed also by changes in the $J_{\mathrm{SC}} / J_{\mathrm{PH}}$ and (as discussed later) in $n$. Such parameters are known to be related with the junction properties of the active layer [56]. We must also remember that $V_{\mathrm{OC}}$, along with the $J_{\mathrm{SC}}$, is crucial for the increase in the solar cell efficiency and, on an ideal condition, to allow the cell to have an even higher, although theoretical, power production.

One of the key points of a solar cell performance is the maximum power point (MPP) where the cell produces the highest electrical power. This is obtained by multiplying both the produced current and voltage throughout the entire $J-V$ curve. The highest value resulting from this product, in the curve region where electric power is actually produced, is the MPP, and $J_{\max }$ and $V_{\max }$ are the current density and the voltage at the MPP, respectively. Taking into account that this parameter is current and voltage dependent and considering that the current density $J$ (and therefore $J_{\max }$ ) drops significantly while $V_{\mathrm{OC}}$ is smoothly increasing the widening of the $J-V$ curve on the voltage axis, the new $V_{\max }$ points are relatively constant. The result is a decrease in the $P_{\max }$ by area $\left(W / \mathrm{cm}^{2}\right)$.

The observed losses results on a serious crop on the performance of the device. As more intrinsic defects play a role on the carrier generation/transport, once these are exposed to the incident radiation, the effect can be seen through the curve shape as the device gradually loses its ability to maintain a good fill factor. A solar cell fill factor can be easily obtained by $[57,58]$ Fill factor $=\left(J_{\max } \times V_{\max }\right) /\left(J_{\mathrm{SC}} \times V_{\mathrm{OC}}\right)$. From the initial $55.7 \%$ of FF (Figure 4(a)), as the active area rises, the rectification of the device decreases rapidly substituting the desired "L-shape" of the $J-V$ curve by a line that resembles a linear $J-V$ behavior.

The efficiency of a solar cell $\eta$ can be easily given by $[51,57] \eta=P_{\max } / P_{\mathrm{IN}}=\left(\left(V_{\mathrm{OC}} \times J_{\mathrm{SC}}\right) / P_{\mathrm{IN}}\right) \times \mathrm{FF}$ where $P_{\mathrm{IN}}$ is the incident solar power by area. In our case, the active area increase causes a nearly exponential drop of $\eta$ as seen in Figure 4(b) going from the initial $2.8 \%$ to $0.5 \%$ efficiency.

Despite the increase in open-circuit voltage, the losses in the current seriously affect the device fill factor as it can be seen in Figure 4(a). Usually, bulk recombination and intrinsic defects modeled by the parallel resistance $\left(R_{\mathrm{P}}\right)$ are the major precursor for the FF drop, and we expect that the series resistance increases its value to cause some device performance fluctuations. In Figure 5(a), the increase in the $R_{\mathrm{S}}$ (adjusted by area, i.e., $R_{\mathrm{S}} \times$ area) with the increase of the device area (in a linear relationship) is shown, while in Figure 5(b), we can observe that the value of $R_{\mathrm{P}}$ (in the same conditions) was kept relatively constant with the area increase. Since parallel resistances model leakage currents occurring in the device and recombination on the bulk heterojunction, it is clear from Figure 5(b) that the increase of active area does not add much more recombination and, in the first explanation, is not responsible for the lowering of the efficiency. 


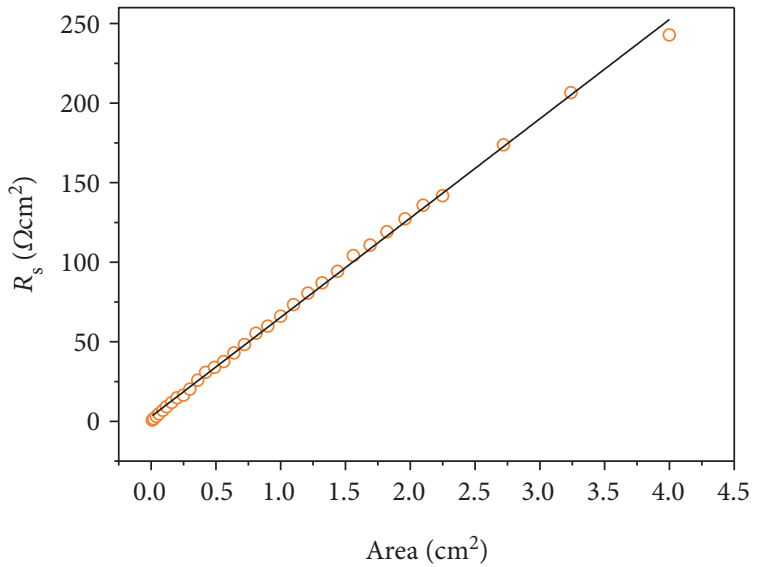

(a)

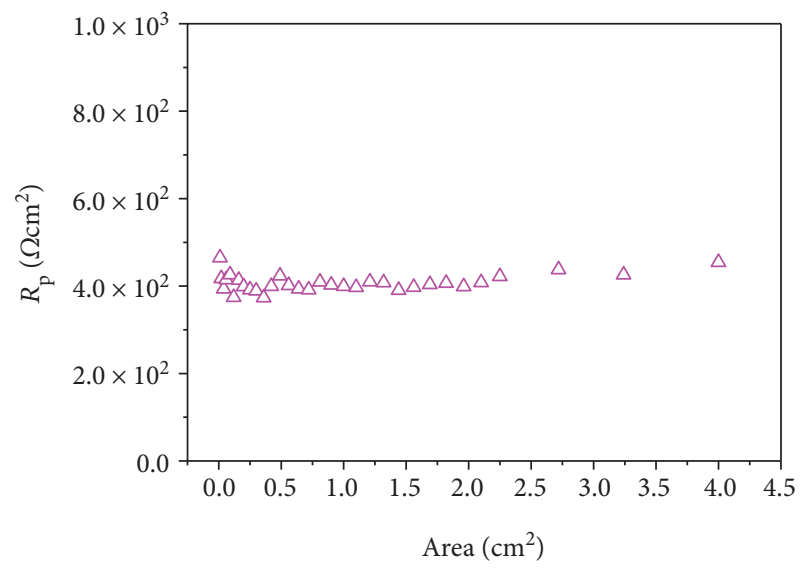

(b)

Figure 5: (a) Device series resistance value related to the active area. A linear relationship between $R_{\mathrm{s}}$ and device area is observed. (b) Device parallel resistance was kept almost constant with active area increase.

To retrieve information regarding the diode quality, its ideality factor $(n)$ gives a good feedback regarding the molecular conformation and device efficiency on electron hole pair generation and can be seen to be linked to both FF and cell efficiency. The ideality factor seems also to be dependent when the area increases, although not represented here. As widely known, $n=1$ represents a perfect crystalline mesh with no structural defects [59]. Usually, we consider that the ideality factor is related with the diode behavior with the applied voltage when considering the open situation and the diode recombination behavior [60]. In the case of BHJ solar cells, the cases of $n>2$ are usually treated as tunneling effects [61] or eventually related with the reduced mobility typical from disordered materials. Considering the fact that organic material conformation is difficult if not impossible to control, in the smallest area, an ideality factor of 2.1 was achieved, which is a relatively good demonstration, for amorphous materials, of the local conformation where this device area was initially studied. As soon as the area is increased, the density of defects under illumination on the device increases as well quickly "reducing" (increasing) the ideality factor from its ideal value (for an area of $4 \mathrm{~cm}^{2}, n$ is about 6 in a relatively linear relationship). Such behavior suggests that other mechanisms can be responsible for the recombination losses at the bulk heterojunctions. For instance, nonoverlapping orbitals or different environmental conformations can lead to the existence of several charge traps that end up reducing drastically charge transport through the different donor-acceptor molecular hopping.

Considering now the overall figures of merit from our devices, we can see that both $J_{\mathrm{SC}}$ (and $J_{\mathrm{PH}}$ ) and FF decrease significantly while $V_{\mathrm{OC}}$ remains relatively constant. The reduction of the $J_{\mathrm{SC}}$ can be easily attributed to the possible existence of inhomogeneity in the thin film morphology that reduces the exciton separation. Taking into account such possible nonuniformities in the active area that increases the series resistance, it seems to be also correct to list the decrease of $\eta$ as arising from the FF behavior, which clearly decreases while increasing the active area. Considering the

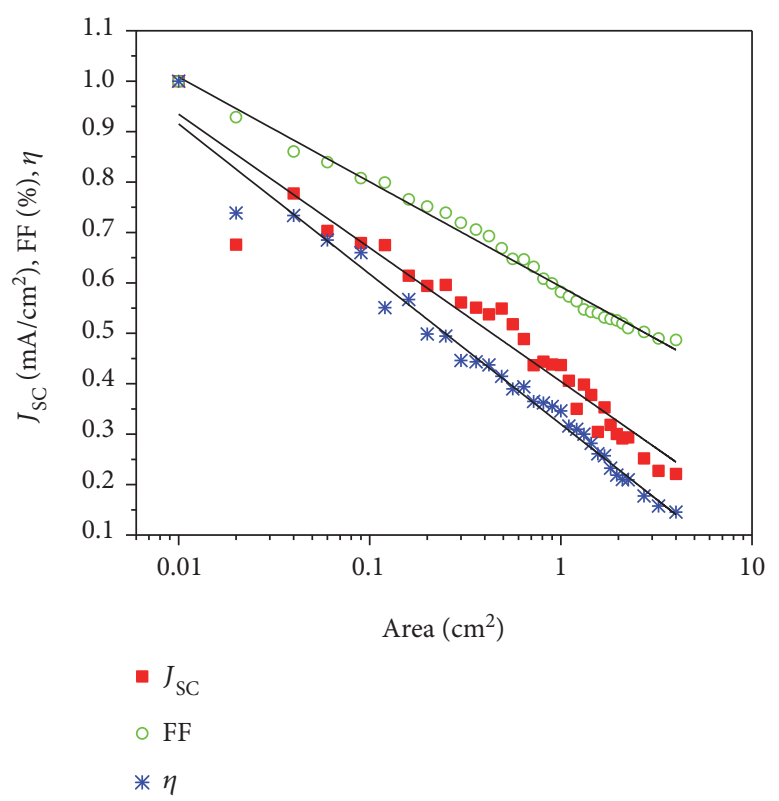

FIGURE 6: Normalized logarithmic scale for efficiency $(\eta), \mathrm{FF}$, and $J_{\text {SC }}$. See text for more information.

behavior of $J_{\mathrm{SC}}, \mathrm{FF}$, and $\eta$, a logarithmic plot of their normalized values can be made (Figure 6) and it is obvious that the changes in $\eta$ seem to be more correlated with the $J_{\mathrm{SC}}$ behavior than the observed in FF. Nevertheless, both depends on exciton separation $\left(J_{P H}\right.$ related) and must be the focus. The relationship with FF can be an outlined way for a final assumption.

Some other factors must be taken into account. Several attempts to explain the efficiency versus area behavior of organic solar cell has been made namely a poor film quality with the effect of the series resistance $[42,43,52,62]$. On the other hand, we must also take into account the possible joint effect of the series resistance with some possible physical factors that can accelerate the donor-acceptor recombination, usually related with structural defect states in the polymers 


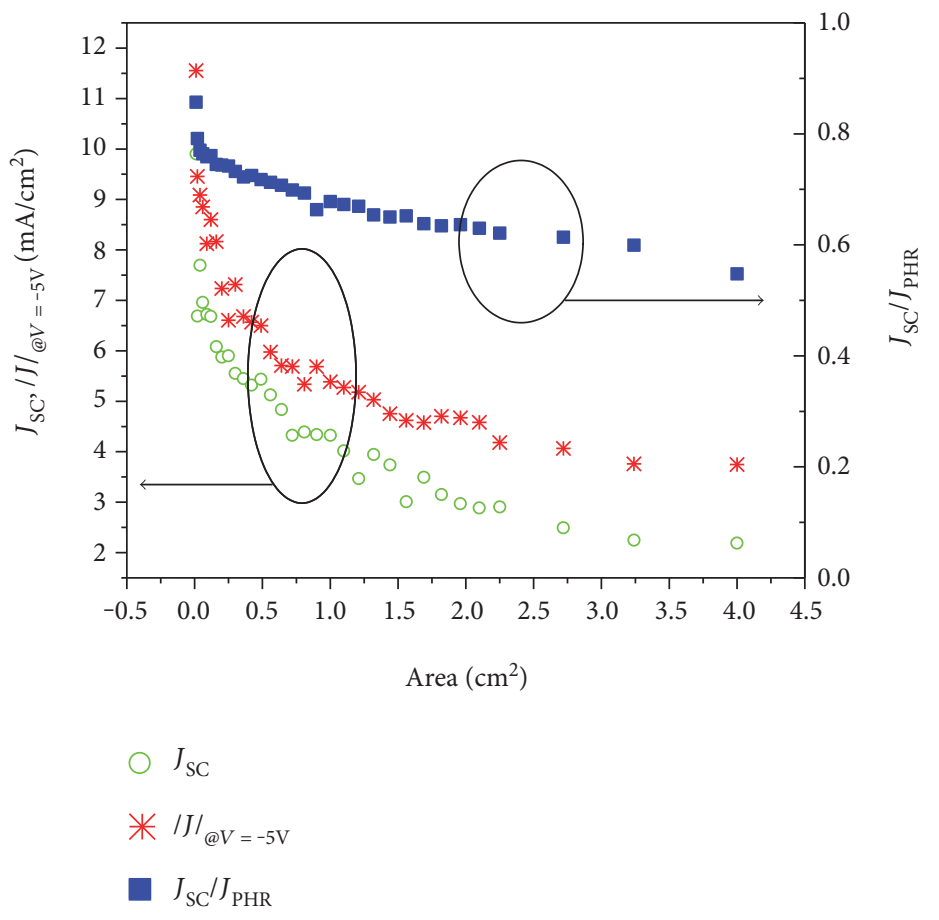

FIGURE 7: $J_{\mathrm{SC}} / J_{\mathrm{PHR}}$ and $J_{\mathrm{SC}}, J_{\mathrm{PHR}}$ as a function of device active area.

used to build the BHJ device [44]. From Figure 6, it is very interesting to extract the fitting parameters giving a simple empirical variation. We have $\eta_{\text {area }}=0.32 \exp (-0.29 \times$ area $)$, $\mathrm{FF}_{\text {area }}=0.56 \exp (-0.2 \times$ area $)$, and $J \mathrm{sc}_{\text {area }}=0.4 \exp (-0.26 \times$ area). Obviously, this kind of device can give a real idea about what we can expect in the scaling up.

The decrease of $J_{\mathrm{SC}}$ is naturally related with $J_{\mathrm{PH}}$ behavior (Figure 3(a)). As reported by some authors (e.g., [52]), $J_{\mathrm{PH}}$ is usually dependent on voltage, particularly under high power light excitation (for instance above one Sun). This behavior is the natural consequence of the loss in exciton separation, a typical and well-known problem in organic photovoltaics, mainly due to the decrease of the charge transfer state generation dissociation (CTS, creation of free electron hole pairs) leading to a decrease of $J_{\mathrm{PH}}$ (and therefore changing the remaining figures of merit accordingly). This effect becomes more important as the active area increases. In fact, while increasing the active area, the electrical filed across the OPV becomes much more nonuniform (mainly due to the ITO distributive resistance) and this effect limits the $J_{\mathrm{PH}}$ with further loss in $J_{\mathrm{SC}}$. Even in the simplified case of $J_{\mathrm{PH}}$ voltage independent $((1))$, we should expect a decrease of overall figures of merit. Moreover, we expect that when $J_{\mathrm{SC}}$ decreases, it will follow, according the abovementioned discussion, the $J_{\mathrm{PH}}$ behavior. This is observed in our case, and for an analytical comparison at low illumination power (up to one Sun), (1) can be used. On the other hand, when increasing the active area, additional loss mechanisms appear, if nonuniform illumination effects become more pronounced. It is interesting to note that with the changes in contacts resistance distribution by means of different device structures, in a similar way, the present work can be extracted $[63,64]$.
Although much relevant with solar panels where contacts geometry is important, or efficiency of sun concentrators, we cannot discard such influences on our case, in spite of the low incident light power and similar contacts geometry for all devices. The problem can be focused on organic layer inhomogeneity as discussed.

Some influence of the active area inhomogeneity can be partially reduced when we analyze the $J_{\mathrm{SC}} / J_{\mathrm{PHR}}$, where $J_{\mathrm{PHR}}$ is the $J$ at relatively high reverse bias. Some similar approach was successfully made by some authors [44]. In Figure 7, the relationship $J_{\mathrm{SC}} / J_{\mathrm{PHR}}$ is shown, in addition to $J_{\mathrm{SC}}$ and $|J| @-5 \mathrm{~V}\left(J_{\mathrm{PHR}}\right)$. From the typical $J-V$ model, we expect that $J_{\mathrm{SC}} / J_{\mathrm{PHR}}$ must be kept constant. This is not really observed. However, the $J_{\mathrm{SC}}$ and FF does not reduce linearly with the area increase. Therefore, in a good approximation, we can consider that the reduction in $J_{\mathrm{SC}}\left(J_{\mathrm{PH}}\right.$ related and, by consequence, $\mathrm{FF}$ ) is the main factor for lowering the efficiency and not the series resistance. As a simple conclusion (and considering the $J-V$ model circuit), the basic system fails to describe the area dependence results. The loss of $J_{\mathrm{SC}}$ can be therefore related to an "accelerated" D-A recombination probably due to defect states where collection charge depends on the local environment found at the active area (and light incidence dependent). Moreover, the carrier generation $\left(J_{\mathrm{PH}}\right)$ is correlated with this assumption. As an overall conclusion, the final efficiency of an OPV "reliable area" depends on the active film internal recombination process: CTS dissociation (free electron hole pairs) and charge transport. In increasing active areas, such process governs the overall OPV macroscopic behavior and can be related with the enlargement of defect interaction in electrically molecular active overlapping. 
Independently, on the pure physical intrinsic behavior of organic layers mentioned above, the contact distributive resistance effect is evident in large active areas and will be always a real question. Although it is not the focus of the present work (the device structure/shape is always the same for all areas in order to keep a common line), changing the shape contact structure and/or unitary cell can help to reduce the loss in a large area OPV. The decrease of $J_{\mathrm{PH}}$ will always be a constraint. Nevertheless, a uniform electrical field at electrodes (and in this case the ITO) can give some solution. Our recent work in simulation of charge distribution at ITO surface covered with gold metal grid (or even in PEDOT:PSS instead ITO) shows a more uniform distributed resistance up to active areas near $1 \mathrm{~cm}^{2}$, but although with less influence, the problem persists for high active areas. On the other side, to avoid high losses in $J_{\mathrm{PH}}$, (and therefore in $J_{\mathrm{SC}}$ and efficiency) in a simple OPV device (without any particular "ordered" HBJ layer), the final optimization towards a "useful" active area must fulfil the requirements of low trapping defect density (as also suggested by our previous results with small signal and capacitance-voltage data). The local molecular conformation can be improved by using careful postthermal annealing and changing the deposition layer parameters/polymer solution properties, as our actual work on continuous roll-to-roll depositions shows.

\section{Conclusions}

The use of small-area laboratory devices is important for performing the initial analysis of materials and other physical studies regarding the performance of organic bulk heterojunction solar cells. However, such dimensions are not appropriate when considering architectures for large-scale final devices or prototypes. In this study, we approached the active area growth from a typical lab scale to a manufacturing scale using the simplest architecture for a $\mathrm{BHJ}$ device. The behaviors of the cells were successfully modeled using our algorithms and allowed for a comparison of the cell behavior evolution with the area increase. The significant drop in efficiency, as cell active area increases, can be assigned to the decrease of $J_{\mathrm{SC}} / \mathrm{FF}$, both correlated with the generated photocurrent. There seems to be always a tradeoff whenever considering the advantages of small area cells and large area cells, and from the reported experimental data, this has been proven. Further studies and optimizations to the morphology of these devices must consider the data now analyzed to decide strategies to approach these materials/architecture limitations.

\section{Disclosure}

Some preliminary concepts of this work were presented as a poster in X Brazilian MRS Meeting, September 25-29, Gramado, Brazil (2011).

\section{Conflicts of Interest}

The authors declare that there is no conflict of interest regarding the publication of this paper.

\section{Acknowledgments}

The authors would like to thank Mr. M. Santos for his help in some experimental measurements.

\section{References}

[1] G. Yu, C. Zhang, and A. J. Heeger, "Dual-function semiconducting polymer devices: Light-emitting and photodetecting diodes," Applied Physics Letters, vol. 64, p. 1540, 1994.

[2] G. Dennler, M. C. Scharber, and C. J. Brabec, "Polymerfullerene bulk-heterojunction solar cells," Advanced Materials, vol. 21, pp. 1323-1338, 2009.

[3] A. J. Medford, M. R. Lilliedal, M. Jorgensen et al., "Gridconnected polymer solar panels: initial considerations of cost, lifetime, and practicality," Optics Express, vol. 18, Supplement 3, pp. A272-A285, 2010.

[4] F. C. Krebs, T. Tromholt, and M. Jorgensen, "Upscaling of polymer solar cell fabrication using full roll-to-roll processing," Nanoscale, vol. 2, pp. 873-886, 2010.

[5] W. Ma, C. Yang, X. Gong, K. Lee, and A. J. Heeger, “Thermally stable, efficient polymer solar cells with nanoscale control of the interpenetrating network morphology," Advanced Functional Materials, vol. 15, pp. 1617-1622, 2005.

[6] M. Reyes-Reyes, K. Kim, and D. L. Carrol, "High-efficiency photovoltaic devices based on annealed poly(3-hexylthiophene) and 1-(3-methoxycarbonyl)-propyl-1-phenyl-(6,6)C61 blends," Applied Physics Letters, vol. 87, article 083506, 2005.

[7] C. J. Brabec, S. Gowrisanker, J. J. M. Halls, D. Laird, S. Jia, and S. P. Williams, "Polymer-fullerene bulk-heterojunction solar cells," Advanced Materials, vol. 22, pp. 3839-3856, 2010.

[8] Z. He, C. Zhong, X. Huang et al., "Simultaneous enhancement of open-circuit voltage, short-circuit current density, and fill factor in polymer solar cells," Advanced Materials, vol. 23, pp. 4636-4643, 2011.

[9] T. D. Nielsen, C. Cruickshank, S. Foged, J. Thorsen, and F. C. Krebs, "Business, market and intellectual property analysis of polymer solar cells," Solar Energy Materials and Solar Cells, vol. 94, pp. 1553-1571, 2010.

[10] G. Li, V. Shrotriya, J. Huang et al., "High-efficiency solution processable polymer photovoltaic cells by self-organization of polymer blends," Nature Materials, vol. 4, pp. 864-868, 2005.

[11] M. C. Scharber and N. S. Sariciftci, "Efficiency of bulkheterojunction organic solar cells," Progress in Polymer Science, vol. 38, p. 1929, 2013.

[12] J. Yang, D. Vak, N. Clark et al., "Organic photovoltaic modules fabricated by an industrial gravure printing proofer," Solar Energy Materials Solar Cells, vol. 109, pp. 47-55, 2013.

[13] J. J. van Franeker, W. P. Voorthuijzen, H. Gorter et al., "All-solution-processed organic solar cells with conventional architecture," Solar Energy Materials and Solar Cells, vol. 117, pp. 267-272, 2013.

[14] F. C. Krebs and M. Jørgensen, "Polymer and organic solar cells viewed as thin film technologies: what it will take for them to become a success outside academia," Solar Energy Materials and Solar Cells, vol. 119, pp. 73-76, 2013.

[15] M. Jørgensen, J. E. Carlé, R. R. Søndergaard et al., “The state of organic solar cells-a meta analysis," Solar Energy Materials and Solar Cells, vol. 119, pp. 84-93, 2013. 
[16] F. C. Krebs, J. Fyenbo, D. M. Tanenbaum et al., "The OE-A OPV demonstrator anno domini 2011," Energy \& Environmental Science, vol. 4, p. 4116, 2011.

[17] C. M. Proctor, M. Kuik, and T. Q. Nguyen, "Charge carrier recombination in organic solar cells," Progress in Polymer Science, vol. 38, pp. 1941-1960, 2013.

[18] J. Y. Kim, K. Lee, N. E. Coates et al., "Efficient tandem polymer solar cells fabricated by all-solution processing," Science, vol. 317, pp. 222-225, 2007.

[19] A. W. Hains and T. J. Marks, "High-efficiency hole extraction/ electron-blocking layer to replace poly(3,4-ethylenedioxythiophene):poly(styrene sulfonate) in bulk-heterojunction polymer solar cells," Applied Physics Letters, vol. 92, article 023504, 2008.

[20] S. H. Park, A. Roy, S. Beaupre et al., "Bulk heterojunction solar cells with internal quantum efficiency approaching 100\%," Nature Photonics, vol. 3, pp. 297-302, 2009.

[21] H. Zhou, Y. Zhang, C. K. Mai et al., "Polymer homo-tandem solar cells with best efficiency of 11.3\%," Advanced Materials, vol. 27, pp. 1767-1773, 2015.

[22] Y. Galagan, I. G. de Vries, A. P. Langen et al., “Technology development for roll-to-roll production of organic photovoltaics," Process Intensification, vol. 50, pp. 454-461, 2011.

[23] T. T. Larsen-Olsen, T. R. Andersen, B. Andreasen et al., "Roll-to-roll processed polymer tandem solar cells partially processed from water," Solar Energy Materials and Solar Cells, vol. 97, pp. 43-49, 2012.

[24] M. Manceau, D. Angmo, M. Jørgensen, and F. C. Krebs, "ITOfree flexible polymer solar cells: from small model devices to roll-to-roll processed large modules," Organic Electronics, vol. 12, pp. 566-574, 2011.

[25] F. C. Krebs, "Polymer solar cell modules prepared using rollto-roll methods: knife-over-edge coating, slot-die coating and screen printing," Solar Energy Materials and Solar Cells, vol. 93, pp. 465-475, 2009.

[26] M. C. Scharber, D. Mühlbacher, M. Koppe et al., "Design rules for donors in bulk-heterojunction solar cells-towards $10 \%$ energy-conversion efficiency," Advanced Materials, vol. 18, pp. 789-794, 2006.

[27] Y. Liang, Z. Xu, J. Xia et al., "For the bright future-bulk heterojunction polymer solar cells with power conversion efficiency of 7.4\%," Advanced Materials, vol. 22, pp. E135E138, 2010.

[28] R. F. Service, "Outlook brightens for plastic solar cells," Science, vol. 332, p. 293, 2011.

[29] W.-J. Yoon and P. R. Berger, "4.8\% efficient poly(3-hexylthiophene)-fullerene derivative (1:0.8) bulk heterojunction photovoltaic devices with plasma treated $\mathrm{AgO}[\mathrm{sub} \mathrm{x}] /$ indium tin oxide anode modification," Applied Physics Letters, vol. 92, article 013306, 2008 .

[30] H.-H. Lia, L.-M. Chen, Z. Xu, G. Li, and Y. Yang, "Highly efficient inverted polymer solar cell by low temperature annealing of Cs2CO3 interlayer," Applied Physics Letters, vol. 92, article 173303, 2008.

[31] T.-Y. Chu, S. Alem, P. G. Verly et al., "Highly efficient polycarbazole-based organic photovoltaic devices," Applied Physics Letters, vol. 95, article 063304, 2009.

[32] C. Waldauf, M. Morana, P. Denk et al., "Highly efficient inverted organic photovoltaics using solution based titanium oxide as electron selective contact," Applied Physics Letters, vol. 89, article 233517, 2006.
[33] M. J. Im, S. Y. Son, B. J. Moon, G.-Y. Lee, J. H. Kim, and T. Park, "Improved photovoltaic performance by enhanced crystallinity of poly(3-hexyl)thiophene," Organic Electronics, vol. 14, pp. 3046-3051, 2013.

[34] G. Dennler, M. C. Scharber, and C. J. Brabec, "Polymer-fullerene bulk-heterojunction solar cells," Advanced Materials, vol. 2, pp. 1323-1338, 2009.

[35] A. B. Tamayo, X. Dang, B. Walker, J. Seo, T. Kent, and T. Nguyen, "A low band gap, solution processable oligothiophene with a dialkylated diketopyrrolopyrrole chromophore for use in bulk heterojunction solar cells," Applied Physics Letters, vol. 94, article 103301, 2009.

[36] R. B. Ross, C. M. Cardona, D. M. Guldi et al., "Endohedral fullerenes for organic photovoltaic devices," Nature Materials, vol. 8, pp. 208-212, 2009.

[37] H.-Y. Chen, J. Hou, S. Zhang et al., "Polymer solar cells with enhanced open-circuit voltage and efficiency," Nature Photonics, vol. 3, pp. 649-653, 2009.

[38] S. Choi, W. J. Potscavaje Jr, and B. Kippelen, "Area-scaling of organic solar cells," Journal of Applied Physics, vol. 106, article 054507, 2009.

[39] D. Gupta, M. Bag, and K. S. Narayan, "Area dependent efficiency of organic solar cells," Applied Physics Letters, vol. 93, article 163301, 2008.

[40] J. D. Servaites, S. Yeganeh, T. J. Marks, and M. A. Ratner, "Efficiency enhancement in organic photovoltaic cells: consequences of optimizing series resistance," Advanced Functional Materials, vol. 20, pp. 97-104, 2010.

[41] J.-S. Yeo, J.-M. Yun, S.-S. Kim, D.-Y. Kim, J. Kim, and S.-I. Na, "Variations of cell performance in ITO-free organic solar cells with increasing cell areas," Semiconductor Science and Technology, vol. 26, article 034010, 2011.

[42] T. Kraft, J.-M. Nunzi, and B. Ratier, "Large Area Fabrication of Polymer Solar Cells," in 40th Physical Organic Mini-Symposium, Kingston, Canada, November 2012.

[43] A. K. Pandey, J. M. Nunzi, B. Ratier, and A. Moliton, "Size effect on organic optoelectronics devices: example of photovoltaic cell efficiency," Physics Letters A, vol. 372, pp. 1333-1336, 2008.

[44] W.-l. Jeong, J. Lee, S.-Y. Park, J.-W. Kang, and J.-J. Kim, "Reduction of collection efficiency of charge carriers with increasing cell size in polymer bulk heterojunction solar cells," Advanced Functional Materials, vol. 21, pp. 343-347, 2011.

[45] A. Cravino, P. Schilinsky, and C. J. Brabec, "Characterization of organic solar cells: the importance of device layout," Advanced Functional Materials, vol. 17, pp. 3906-3910, 2007.

[46] S. M. Sze, Physics of Semiconductors Devices, Wiley-Interscience, New York, NY, USA, 1981.

[47] M. A. Green, Solar Cells: Operating Principles, Technology, and System Applications, Prentice Hall, Englewood Cliffs, NJ, USA, 1982.

[48] Z. Michalewicz, Genetic Algorithm + Data Structures = Evolution Program, Spring-Verlag, Berlin, 3rd edition, 1996.

[49] R. S. Zebulum, M. A. C. Pacheco, and M. M. B. R. Vellasco, Evolutionary Electronics: Automatic Design of Electronic Circuits and Systems by Genetic Algorithms, CRC Pres, Boca Raton, 1st edition, 2001.

[50] K. F. Man, "Genetic algorithms: concepts and applications [in engineering design]," IEEE Transactions on Industrial Electronics, vol. 43, pp. 519-534, 1996. 
[51] A. J. Trindade, M. G. Santos, J. Gomes, and L. Pereira, "The modulation of bulk-organic solar cells: the effect of serial and parallel resistances and the relationship with the microscopic morphology," Materials Research Society Symposium Proceedings, vol. 1359, p. 121, 2011.

[52] A. Manor, E. A. Katz, T. Tromholt, B. Hirsch, and F. C. Krebr, "Origin of size effect on efficiency of organic photovoltaics," Journal of Applied Physics, vol. 109, article 074508, 2011.

[53] P. Kumar, S. C. Jain, H. Kumar, S. Chand, and V. Kumar, "Effect of illumination intensity and temperature on open circuit voltage in organic solar cells," Applied Physics Letters, vol. 94, article 183505, 2009.

[54] V. D. Mihailetchi, P. W. M. Blom, J. C. Hummelen, and M. T. Rispens, "Cathode dependence of the open-circuit voltage of polymer:fullerene bulk heterojunction solar cells," Journal of Applied Physics, vol. 94, pp. 6849-6854, 2003.

[55] C. J. Brabec, A. Cravino, D. Meissner et al., "Origin of the open circuit voltage of plastic solar cells," Advanced Functional Materials, vol. 11, pp. 374-380, 2001.

[56] D. Cheyns, J. Poortmans, P. Heremans et al., "Analytical model for the open-circuit voltage and its associated resistance in organic planar heterojunction solar cells," Physical Review $B$, vol. 77, article 165332, 2008.

[57] A. L. Fahrenbruch and R. H. Bube, Fundamentals of Solar Cells, Academic, New York, USA, 1983.

[58] J. Nelson, The Physics of Solar Cells, Imperial College Press, London, England, 2003.

[59] Y. Roichman and N. Tessler, "Generalized Einstein relation for disordered semiconductors-implications for device performance," Applied Physics Letters, vol. 80, pp. 1948-1950, 2002.

[60] C. Waldauf, M. C. Scharber, P. Schilinsky, J. A. Hauch, and C. J. Brabec, "Physics of organic bulk heterojunction devices for photovoltaic applications," Journal of Applied Physics, vol. 99, article 104503, 2006.

[61] A. Kumar, R. Devine, C. Mayberry, B. Lei, G. Li, and Y. Yang, "Origin of radiation-induced degradation in polymer solar cells," Advanced Functional Materials, vol. 20, pp. 27292736, 2010.

[62] M. Al-Ibrahim, H. K. Roth, and S. Sensfuss, "Efficient largearea polymer solar cells on flexible substrates," Applied Physics Letters, vol. 85, pp. 1481-1483, 2004.

[63] E. A. Katz, J. M. Gordon, W. Tassew, and D. Feuermann, "Photovoltaic characterization of concentrator solar cells by localized irradiation," Journal of Applied Physics, vol. 100, article 044514, 2006.

[64] A. Manor, E. A. Katz, R. Andriessen, and Y. Galagan, "Study of organic photovoltaics by localized concentrated sunlight: towards optimization of charge collection in large-area solar cells," Applied Physics Letters, vol. 99, article 173305, 2011. 

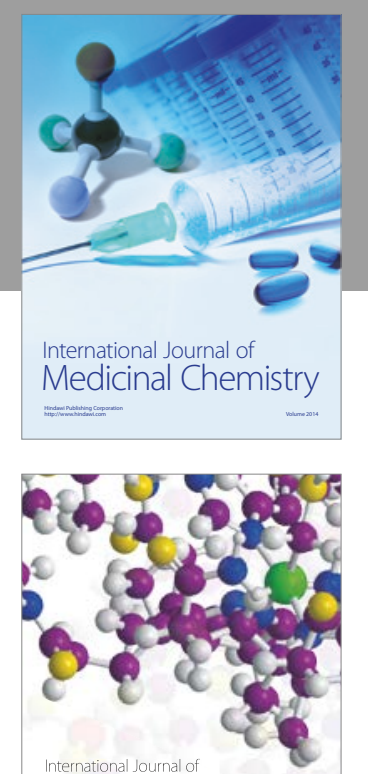

Carbohydrate Chemistry

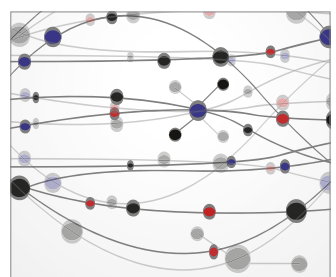

The Scientific World Journal
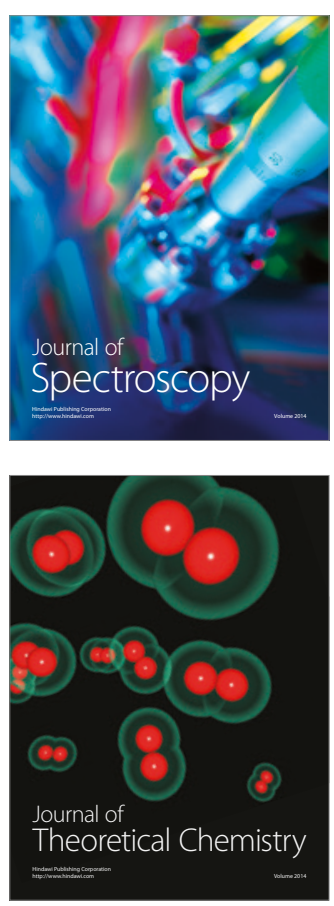
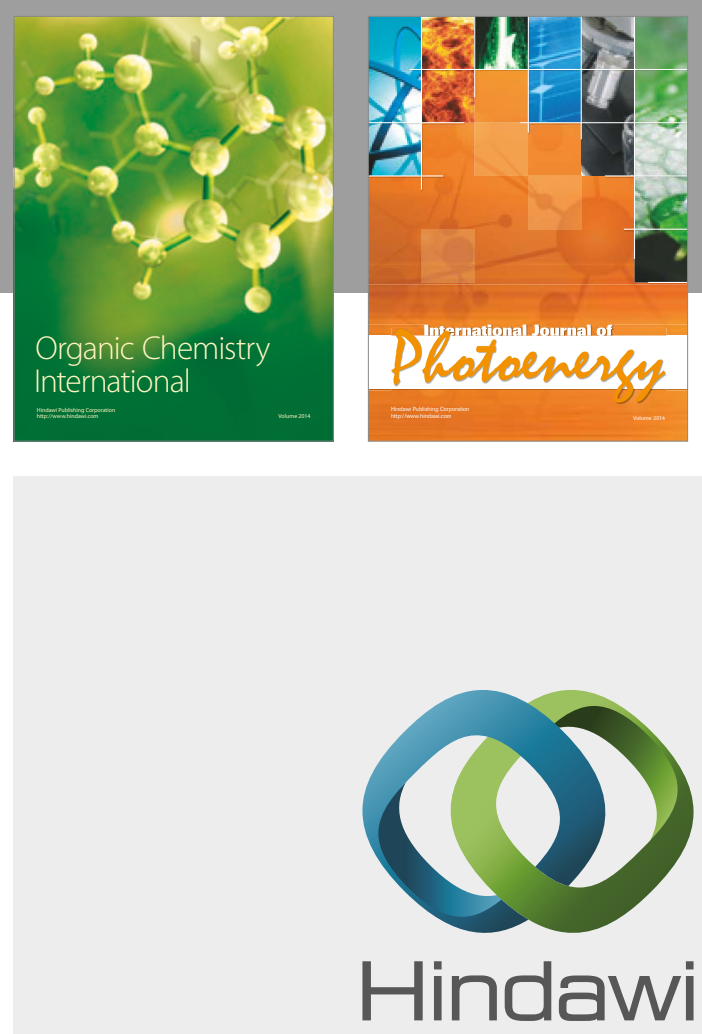

Submit your manuscripts at

https://www.hindawi.com

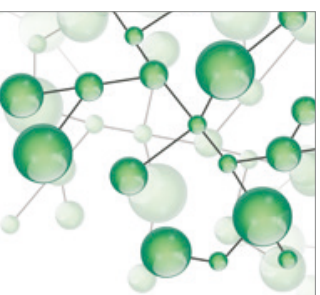

International Journal of

Inorganic Chemistry

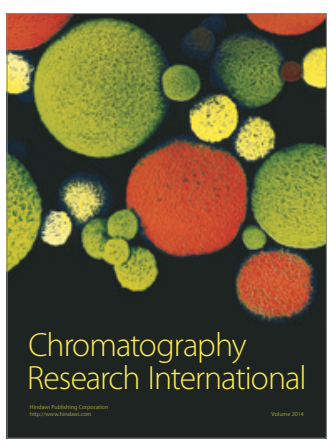

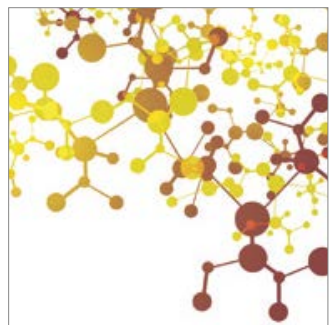

Applied Chemistry
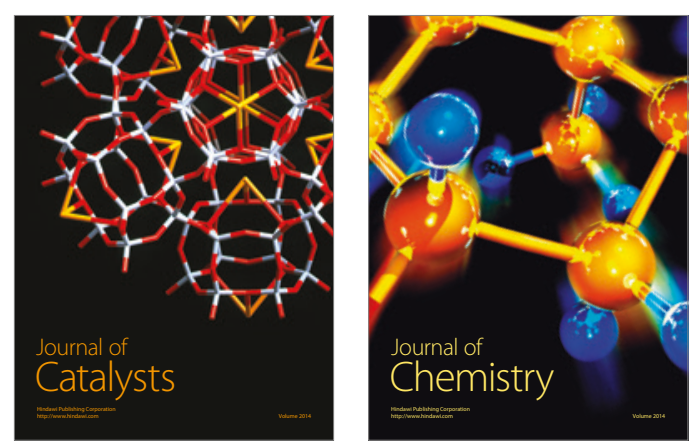
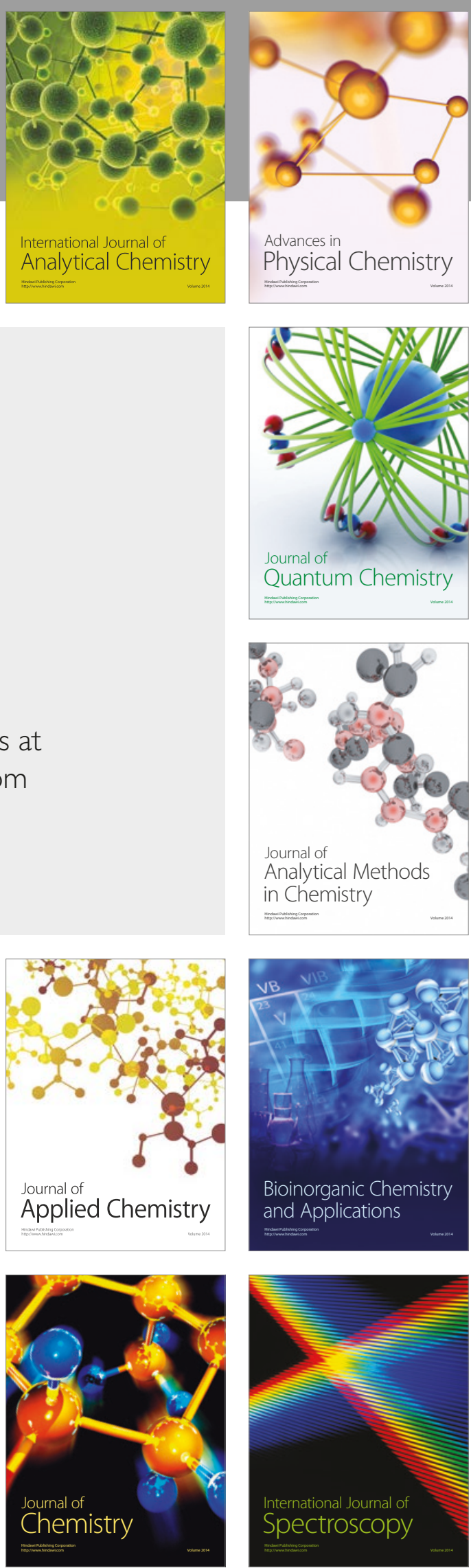